\title{
A AUTONOMIA FRENTE À HIDRA CAPITALISTA: APORTES DA EXPERIÊNCIA ZAPATISTA
}

\author{
Renata Ferreira da Silveira* \\ Universidade Federal do Rio Grande do Sul \\ Marcelo Argenta Câmara** \\ Universidade Federal do Rio Grande do Sul
}

Resumo: O movimento zapatista mexicano, surgido à luz pública no início de 1994, construiu uma trajetória de progressiva territorialização de sua concepção de sociedade e, consequentemente, de sua estratégia de mobilização. Tal trajetória tem sua conclusão (provisória) na constituição dos Caracóis enquanto recortes territoriais autônomos, e das Juntas de Bom Governo enquanto instâncias políticas e sociais de condução da vida em sociedade. Este artigo toma como ponto de partida a reflexão sobre a experiência zapatista para nos questionarmos sobre as possibilidades de respostas à atual crise civilizatória capitalista.

Palavras-chave: Zapatismo. Territorialidades. Autonomia. Capitalismo.

\section{AUTONOMY AGAINST THE CAPITALIST HYDRA: CONTRIBUTIONS FROM THE ZAPATISTA EXPERIENCE}

Abstract: The mexican zapatista movement, which emerged in the public light at the beginning of 1994, has built a trajectory of progressive territorialization of its conception of society and, consequently, of its mobilization strategy. Such a trajectory has its (provisional) conclusion in the constitution of the Caracoles as autonomous territorial divisions, and of the Juntas de Buen Gobierno as political and social instances of conducting life in society. This article takes as its starting point the reflection on the zapatista experience to question ourselves on the possibilities of answers to the current capitalist civilizational crisis.

Keywords: Zapatismo. Territorialities. Autonomy. Capitalismo.

\section{LA AUTONOMÍA FRENTE A LA HIDRA CAPITALISTA: APORTES DE LA EXPERIENCIA ZAPATISTA}

Resumen: El movimiento zapatista mexicano, surgido a la luz pública a principios de 1994, construyó una trayectoria de progresiva territorialización de su concepción de sociedad y, consecuentemente, de su estrategia de movilización. Tal trayectoria tiene su conclusión (provisional) en la constitución de los Caracoles como recortes territoriales autónomos, y de las Juntas de Buen Gobierno como instancias políticas y sociales de conducción de la vida en sociedad. Este artículo toma como punto de partida la reflexión sobre la experiencia zapatista para preguntarse sobre las posibilidades de respuestas a la actual crisis civilizatoria capitalista.

Palabras clave: Zapatismo. Territorialidades. Autonomía. Capitalismo. 
No basta con avisar lo que vemos. Tenemos que decir también quiénes somos los que vemos. Porque los cambios que avistamos no son sólo allá afuera. Nuestra mirada hacia dentro también detecta cambios, y nuestra propia mirada ha cambiado. Entonces queda claro que, para explicar lo que miramos, tenemos que explicar nuestra mirada.

(...) No sólo alertamos sobre lo que se mira en el horizonte. También tratamos de dar cuenta de la mirada que somos.

$\mathrm{Y}$ entonces vimos que es importante la historia, es decir, cómo era antes; que es lo que sigue igual; que es lo que cambia. O sea, la genealogía.

Y para explicar la genealogía, tanto de lo que somos como de lo que vemos, necesitamos conceptos, teorías, ciencias.

Y para saber si esos conceptos son útiles, es decir, dan cuenta cabal de esa historia, es que necesitamos el pensamiento crítico.

(SupGaleano, 2015, p. 12-13)

\section{Introdução}

Segundo a mitologia greco-romana, os doze trabalhos de Hércules foram um conjunto de tarefas exigidas do famoso personagem para que tivesse acesso definitivo ao Olimpo, morada reservada aos deuses. Filho de Zeus com uma mortal, Hércules era dotado de força descomunal, e esses trabalhos eram tarefas que the exigiram habilidades sobre-humanas. Entre eles, derrotar a hidra de Lerna, animal com corpo de dragão e cabeças de serpente - sete, nove, ou mesmo inúmeras cabeças, a depender da versão do mito -, que, quando cortadas, eram substituídas por uma nova que nascia no lugar da que havia sido decepada.

Em maio de 2015, o Exército Zapatista de Libertação Nacional (EZLN), movimento sediado no estado mexicano de Chiapas, abriu as portas de suas comunidades para receber simpatizantes e apoiadores de diferentes partes do mundo para um seminário internacional batizado "El pensamiento crítico frente a la hidra capitalista". Percebe-se, pelo próprio nome do evento, que, para os e as zapatistas, o capitalismo é como a hidra enfrentada por Hércules. E que, em lugar do mítico semideus, a tarefa de enfrentar o monstro multifacetado cabe, agora, ao pensamento crítico.

Qual(is) seria(m) o(s) significado(s) dessa analogia? Em que, ou como, o capitalismo se parece a uma hidra? E se tomamos a analogia como correta, a quem cabe a tarefa de derrotá-la? Ao movimento zapatista? Ao pensamento crítico?

É possível enumerarmos algumas propostas/ sugestões com a finalidade de encontrar o fio que une essas histórias tão distantes em tempo e origem. Mas talvez, antes, seja necessário responder a outro conjunto de perguntas que se impõe se quisermos conferir legitimidade às analogias que estão sendo propostas.
Pois, afınal, quem são os zapatistas? O que os "credencia" a promover seminários, a convocar a comunidade internacional e, acima de tudo, a provocar o pensamento, a crítica e a ação a partir das reflexões nascidas dessas comunidades remotas dos distantes rincões do sudeste mexicano?

Este artigo propõe uma reflexão, a partir da experiência zapatista - sua trajetória e o pensamento que com ela emerge -, sobre as características do atual momento capitalista. A metodologia aplicada será a mesma sugerida pelos próprios zapatistas, citada na epígrafe deste trabalho: para refletir sobre sua "visão" - a hidra capitalista -, começaremos por explicar o que "são" - o movimento, sua genealogia e sua trajetória - e, nesse percurso, recorreremos à reflexão teórico-conceitual. Através dessa metodologia, buscamos oferecer aportes para a renovação do pensamento crítico e, em especial, do pensamento crítico no campo do conhecimento chamado Geografia.

\section{Breve genealogia do zapatismo (ou, "para explicar lo que miramos, tenemos que explicar la mirada que somos")}

Dotados de uma carga mítica, os e as zapatistas são mundialmente conhecidos e conhecidas. A imagem de um homem ou de uma mulher com o pasamontañas ${ }^{1}$ e um paliacate ${ }^{2}$ já não causa tanto estranhamento e remete, quase sempre, a um certo movimento indígena mexicano, assim como a um certo desconforto nas esferas de poder.

0 movimento tem sua origem na reconfiguração dos setores de esquerda que acontecia, em escala global, no final da década de 1960. O México havia sido palco de um dos episódios mais marcantes do mítico ano de 1968 - o massacre de Tlatelolco -, o que intensificava os questionamentos aos rumos assumidos pela "revolução" sob a condução do Partido Revolucionário Institucional $(P R I)^{3}$. Foi nesse ambiente que, em agosto de 1969, foram fundadas as Forças de Libertação Nacional FLN, grupo guerrilheiro de caráter indígena-maoista com reivindicações voltadas, principalmente, à reforma agrária.

A alta repressão do Estado e as divergências ideológicas internas levaram à crescente desarticulação

\footnotetext{
'Balaclava, gorro de lã que cobre completamente a cabeça de quem o veste deixando apenas os olhos descobertos.

${ }^{2}$ Lenço ornamental de cor predominantemente vermelha, com motivos maias, utilizado sobre os ombros ou cobrindo o rosto.

${ }^{3}$ Fundado ao final da década de 1930, o PRI era o partido que, supostamente, daria prosseguimento às conquistas da Revolução Mexicana a partir de sua institucionalização. 0 apego ao poder, do qual só foi afastado no ano 2000, fez com que seus governos ficassem conhecidos como a "ditadura perfeita", uma vez que conferiam um verniz "democrático" e "revolucionário" ao velho jogo de conchavos da política latino-americana.
} 
da FLN e à constituição de um grupo de cinco guerrilheiros e de uma guerrilheira de origem indígena que decidiram viver nos ambientes de selva das montanhas do estado de Chiapas para lá, possivelmente, articular a formação de um foco de guerrilha. 0 estabelecimento e a convivência desse grupo junto às comunidades maias transformaram o perfil da ação originalmente prevista, com a crescente incorporação de referenciais próprios das culturas locais. Assim, em 17 de novembro de 1983, era fundada a organização clandestina indígena, de caráter militar, Exército Zapatista de Libertação Nacional - EZLN.

Chiapas era, na época, um dos estados mexicanos que vivia de forma mais direta o impacto das transformações políticas e econômicas que antecederam o chamado período neoliberal. A estrutura agrária fortemente camponesa do estado sofria com a pressão por parte das grandes multinacionais mineradoras e do agronegócio pela possibilidade de apropriação do território pela iniciativa privada e/ou dos grandes terratenientes, numa ação legitimada pelo Estado.

As políticas neoliberais que estavam (e ainda estão) sendo implementadas em alguns países da América Latina levaram, no caso do México, ao avanço das negociações para a implantação do Tratado de Livre Comércio com os Estados Unidos e Canadá (NAFTA). Para que houvesse a assinatura do acordo, o México era pressionado a promover uma adequação de sua legislação de forma a retirar empecilhos protecionistas que impedissem a atuação do setor privado estrangeiro no mercado interno mexicano.Assim, em janeiro de 1992, foram anunciadas alterações no artigo 27 da Constituição mexicana, alterando temas fundamentais da estrutura fundiária no país, legados da Revolução Mexicana de princípios daquele século ${ }^{4}$. Com as reformas, os ejidos, terras de propriedade estatal concedidas à posse e usufrutos comunitários inalienáveis, passaram a ter autorizada sua titulação e seu parcelamento, tornandose, assim, um componente na apropriação funcional dos territórios ejidais/indígenas pelo avanço das políticas neoliberais.

O EZLN, que nesse período atuava na clandestinidade, incorpora a insatisfação popular com as reformas conduzidas pelo governo e, após consulta às comunidades tzotzil, chol, tojolabal e tzeltal, decide pela estratégia das armas como forma de exigir o respeito às garantias constitucionais. Assim, no dia 1 de janeiro de 1994, ao mesmo tempo em que era celebrada a formação oficial do Nafta, o movimento zapatista irrompia à luz pública, numa das imagens mais marcantes de qualquer retrospectiva que remeta ao pós-Guerra Fria no que diz respeito à política e aos movimentos sociais contemporâneos: milhares de homens e mulheres, jovens, idosos e crianças, marchando armados e com os rostos encapuzados nas cidades de San Cristobal de Casas, Altamirando, Huixtán, Ocosingo, Las Margaritas, Oxchuc e Chanal. Na sede de cada governo municipal ocupada, os zapatistas leram a "Primeira Declaração da Selva Lacandona", de onde emana a consigna que ficaria célebre: "Ya Basta!".

Figura 1 - Povoados tomados pelo EZLN em 1 de janeiro de 1994

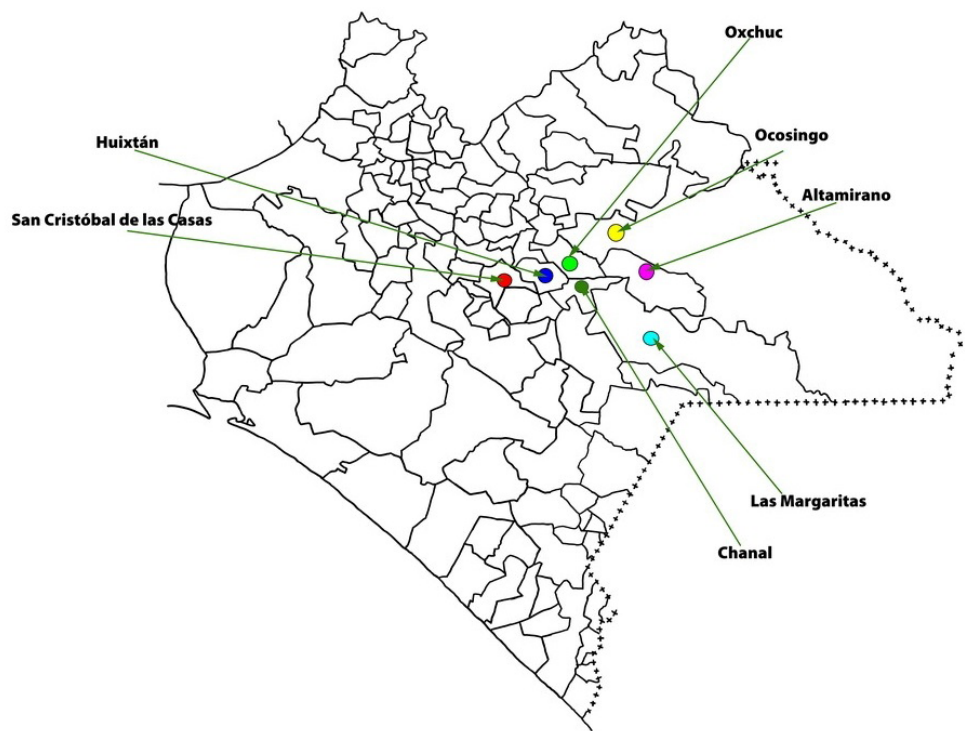

Fonte: Centro de Documentación sobre Zapatismo (http://www.cedoz.org/site/galerias/207.jpg) 
A tática para os zapatistas, na época, foi a de reafirmar o papel da Constituição como documento legitimador dos direitos indígenas, em meio ao avanço das políticas neoliberais em território mexicano. Era, portanto, uma reivindicação através do Estado e uma solicitação de diálogo (ainda que a guerra tenha sido declarada) utilizando, inclusive, o estatuto de cidadania mexicana. $\mathrm{Na}$ Declaração observa-se também, além da publicização da identidade indígena zapatista como motor do EZLN, a conclamação às organizações internacionais para observação e mediação do conflito.

A aparição pública, o levante armado e a "Declaração" são fatos que evidenciam uma concepção estratégica construída no período de clandestinidade para posterior aparição ao mundo. Esses elementos nos apresentam um processo de reconstrução territorial (reterritorialização) a partir da dimensão do simbólico, da luta na escala local e pela construção de um sentido de lugar. Já a escala global traz a proposta de uma geopolítica a partir dos "de baixo", através da formação de territórios-rede que articulem experiências análogas em distintas partes do mundo. Compreende-se, aqui, o uso da tecnologia e da informação como componentes constitutivos da estratégia e da territorialização zapatistas.

As relações geopolíticas, tanto no diálogo entre os Estados nacionais até as relações de movimentos sociais e partidos políticos de esquerda em nível internacional, se aprofundaram com a reação do governo Salinas, que optou por três caminhos: um, guiado pela ação das forças armadas, que executaram centenas de indígenas zapatistas por onde passavam, deixando também um rastro de estupros e de espancamentos; o segundo foi a tentativa de deslegitimação pública do EZLN, afırmandose que os zapatistas estavam a serviço de forças guerrilheiras da América Central e da América do Sul, e sustentando-se que não era um movimento de indígenas e que não os representava, oferecendo, então, anistia para aqueles que "pedissem perdão" e que depusessem as armas (GENNARI, 2005).

$\mathrm{O}$ apelo do EZLN à comunidade internacional e a comoção pública frente à guerra civil e ao massacre proporcionado pelo Estado levaram a mobilizações multitudinárias, tais como a do dia 12 de janeiro daquele ano, quando dezenas de milhares de pessoas marcharam em protesto na Cidade do México para exigir o cessarfogo. Esse momento foi crucial para os zapatistas repensarem o diálogo com a sociedade civil. A partir daí, surgiram dezenas de documentos, declarações, comunicados, convocatórias, livros e eventos que cumpririam o papel de diálogo político com a sociedade civil mexicana e internacional.
Pode-se afirmar que o principal resultado dessa mobilização nacional e internacional foi o surgimento da proposta de cessar-fogo e de abertura de uma mesa de negociações pelo governo Salinas, então sob fortes pressões interna e externa. Os diálogos entre representantes do governo e delegados zapatistas tiveram início em 20 de fevereiro na Catedral de San Cristóbal de Las Casas, período em que o EZLN começava a abrir suas comunidades para o público e para a imprensa, ação vista como estratégica para a qualificação do diálogo com a sociedade civil.

Seis meses após sua aparição pública, era lançado o segundo documento com as posições políticas, aspirações e próximos passos dos zapatistas. As declarações ganharam o tom de documento oficial, e a estratégia colocada agora não apostava mais nas negociações com o Estado e sim na consolidação das comunidades zapatistas e na construção do caráter político do EZLN, para além do caráter militar.

Todavia, a segunda declaração, assim como as demais entrevistas e os documentos desse período, colocava ainda o anseio de que uma nova cultura política vinda dos zapatistas traria, consequentemente, uma nova cultura para os partidos políticos. Buscando uma maior abertura do campo político e a despolarização de um cenário dominado pelo PRI e pelo Partido Acción Nacional (PAN), os zapatistas convocavam à Convenção Nacional Democrática - CND:

\begin{abstract}
Nos dirigimos aos nossos irmãos das organizações não governamentais, das organizações não camponesas e indígenas, trabalhadores do campo e da cidade, professores e estudantes, donas de casa e colonos, artistas e intelectuais, membros dos partidos independentes, mexicanos: os chamamos para um diálogo nacional sobre o tema da Democracia, Liberdade e Justiça. Por isso, estamos lançando este convite para a realização de uma Convenção Nacional Democrática. (EZLN, 2016, p. 77)
\end{abstract}

A proposta da CND era reflexo da conjuntura política mexicana para além da relação Estado versus EZLN, convertendo-se também em tática de reconstrução do Estado a partir da participação da sociedade civil, numa plataforma propositiva e não apenas de diálogo, como vinha acontecendo e que acabava expondo a organização indígena zapatista tanto no aspecto militar como no político e nas relações comunitárias. A CND teve duração de cinco dias (de 5 a 9 de agosto de 1994), e contou com a participação de "cerca de 7 mil pessoas de todos os estados do México, além de centenas de observadores internacionais e representantes dos meios de comunicação, (que) responderam à convocação zapatista" (GENNARI, 2005, p. 53). Porém, as disputas internas entre correntes ideológicas e a sobreposição de 
agendas partidárias nas decisões da CND incapacitaram a tentativa de construção de uma frente ampla de oposição que superasse a política dos partidos. Ainda assim, cabe o reconhecimento de que este foi o primeiro chamado público de organização paralela ao governo e de exposição da organização comunitária zapatista no âmbito internacional, o que resultou no fortalecimento da imagem política e simbólica do EZLN, assim como na formação espontânea de uma rede de solidariedade internacional.

Nos mesmos dias em que acontecia a conferência, foi anunciada a nova estratégia do movimento: a criação dos Aguascalientes, territórios constituídos para serem a sede das atividades político-culturais promovidas pelos zapatistas, como o Fórum Nacional Indígena, o Encontro Nacional de Comitês Civis para o Diálogo Nacional, o Fórum Especial para a Reforma de Estado, o Primeiro Encontro Intercontinental pela Humanidade e contra o Neoliberalismo e o Primeiro Encontro Intergalático (todos ocorridos em 1996), assim como do diálogo e da articulação do movimento com a sociedade civil nacional e internacional, movimentos sociais, partidos, imprensa etc. Foram constituídos cinco Aguacalientes em cinco municípios: La Realidad, Oventic, La Garrucha, Morelia e Roberto Barrios.

Ao mesmo tempo, o EZLN rompia o cerco militar através da criação de 32 Municípios Autônomos Rebeldes Zapatistas (MAREZ). Esses municípios possuíam toda uma institucionalidade paralela à do Estado (registros de nascimento, casamento, escolas, conselho municipal, secretário de assuntos agrários, comitê de saúde, justiça, educação etc.) (ALONSO; ALONSO, 2015, p. 78). Para o governo mexicano, o anúncio desses territórios mais ou menos autogestionados, mais ou menos afinados ideologicamente, significava uma clara afronta ao Estado, e, novamente, o PRI colocou os Aguascalientes e os MAREZ sob ataque das Forças Armadas Nacionais, mesmo com o fim do cerco militar zapatista.

Porém, esta decisão política do PRI teve grande repercussão pública e desencadeou diversas manifestações nacionais e internacionais em solidariedade aos zapatistas. Na sequência dos fatos e com medo da opinião pública, o Estado, através do Poder Legislativo, interveio com a aprovação da "Lei para o diálogo, a conciliação e a paz digna em Chiapas". Com o apoio de parte da população e sob os olhos atentos de organizações sociais internacionais e nacionais, o EZLN e o governo assinaram, em fevereiro de 1996 e como resultado de quatro meses de negociações, os "Acordos de San Andres":

[...] o governo e o EZLN assinaram um documento onde constavam os seguintes compromissos: o reconhecimento, como garantia constitucional, do direito de autodeterminação dos povos indígenas (especialmente levando em conta o fato de o México ser signatário da Convenção 169 da Organização Internacional do Trabalho) ${ }^{5}$; a realização de reformas legais e constitucionais visando ampliar a participação e a representação política local e nacional dos povos indígenas, conformando um novo federalismo; a garantia do acesso pleno dos povos indígenas aos instrumentos jurídicos do Estado, e sua adaptação às suas especificidades culturais e seus sistemas normativos internos. (BRANCALEONE, 2012, p. 262)

Porém, os Acordos não foram respeitados pelo governo mexicano. Ao contrário, ao passo que o governo ignorava os diálogos, diferentes estratégias de enfraquecimento político e de isolamento social eram adotadas contra o EZLN: forças paramilitares instigadas e acobertadas pelo próprio governo - alguns setores mais discretos do exército, forças civis armadas - protagonizavam massacres contra populações indígenas, que viam, ao mesmo tempo, seus protestos serem criminalizados. Essas estratégias fizeram que, além do abatimento do EZLN, surgisse uma nova postura do movimento em relação aos acordos firmados com os partidos políticos (que haviam pressionado pela assinatura dos Acordos, numa tentativa de estabilização do cenário político e social com nítidos fins eleitorais).

Os Aguascalientes também foram, além de agrupamentos maiores de referência para os MAREZ, uma articulação espacial de territórios descontínuos onde "comenzaron a expresar la posibilidad de materializar espacialmente los ideales libertários de justicia y democracia, en un despliegue territorial de regiones autônomas pluri-étnicas" (ITZU LUNA, 2013, p. 117). A autonomia passava a ser, então, a base de princípios e ações na totalidade do movimento. A criação dos MAREZ também representava a territorialização da luta pela autodeterminação dos povos indígenas no México, com toda sua representatividade material e simbólica para a história da luta zapatista. As relações de poder intrínsecas ao território, suas apropriações, manifestações e subjetividades levam a um olhar atento aos sujeitos que estão envolvidos no processo de apropriação do espaço e ao significado a este atribuído por eles (SOUZA, 1995), tecendo, então novas territorialidades.

A configuração dos MAREZ enquanto território político também se amparava, no aspecto jurídico, na implantação de um conjunto de leis, tais como as "Leis Revolucionárias Zapatistas", a "Lei Revolucionária Indígena" e a "Lei Revolucionária das Mulheres". Hibridizavam-se formas de governo comunitárias ${ }^{5}$ Aprovada em junho de 1989, a Convenção sobre Povos Indígenas e Tribais da Organização Internacional do Trabalho, conhecida como Convenção n. 169, é um dos principais documentos de referência no que diz respeito aos direitos coletivos dessas comunidades, versando, em especial, sobre a questão do direito à autogestão autônoma em seus territórios ancestrais. 
tradicionais, de herança maia, com referências mais inovadoras - como no caso da Lei das Mulheres -, o uso intenso de estratégias e tecnologias de comunicação e as relações com organizações não indígenas.

De 2001 até 2003 foram registradas 82 denúncias de violência contra as comunidades zapatistas, sendo que em 2002 aumentaram as ações de paramilitares contra as bases do movimento (ALONSO; ALONSO, 2015). A decisão dos zapatistas diante da violência e da repressão foi de emitirem comunicados e declarações através do Subcomandante Insurgente Marcos dizendo que adotariam as resoluções do acordo de San Andres (ainda que) unilateralmente. Acreditava-se, em meados de 2003, que os zapatistas estavam enfraquecidos e que tinham perdido forças devido aos ataques do Estado e dos paramilitares. Mas, ao contrário, o movimento estava, na verdade, amadurecendo e criando novas estratégias dentro das relações de poder.

A reorganização territorial decidiu, então, por acabar com os Aguascalientes, pois estes não possuíam mais o sentido que se propusera outrora, qual seja, o de espaços de troca de saberes e de desenvolvimento da autonomia para as comunidades zapatistas. Ainda assim, da fundação ao final dos Aguacalientes, passando pela organização dos MAREZ, a ruptura cada vez mais evidente com o Estado se tornava componente fundamental para as novas territorialidades zapatistas.

Enquanto o EZLN guardava um período de silêncio em sua relação com a sociedade civil, os municípios rebeldes foram trabalhando cada vez mais a cultura de resistência e de autonomia, forjando territorialidades a partir da escala local/municipal e da sua organicidade:

[...] desde el inicio [os MAREZ] se definieron no sólo como un espacio que delimitaría el "control territorial", en el sentido de una expresión territorial simbólicopolítica de construcción de una vida de libertad, democracia y justicia desde la dignidad. (ITZU LUNA, 2013, p. 117)

Em 10 de agosto de 2003 foram inaugurados, com grande comemoração, os Caracóis Zapatistas e as Juntas de Bom Governo (JBG) com a função de serem "puertas para entrar las comunidades y para que las comunidades salieram". Ser "como la boca para sacar lejos su palavra y escuchar la del lejos este" (SubCOMANDANTE MARCOS, 2013).

[...] la propuesta zapatista era organizar, en vez de los aguacalientes, los llamados caracoles, nombre de la sede del territorio geográfico que regirían cincos Juntas de Buen Gobierno en los municipios autónomos. (...) se encerraba una pedagogía del zapatismo hacia la sociedad civil. Ante la negativa del estado mexicano de dar pleno reconocimiento a los derechos indígenas y hacer realidad legislativa los acuerdos de San Andrés, los zapatistas anunciaban que harían realidad esos acuerdos en la práctica diaria. De hecho, de esta misma forma habían ido consolidando lentamente sus municipios autónomos. (ALONSO; ALONSO, 2015, p. 208)

E cada Caracol passou a ter novos nomes, com outras simbologias: I - La Realidad: madre de los caracoles del mar de nuestros sueños; II - Morelia: torbellino de nuestras palabras; III - La Garrucha: resistencia hasta un nuevo amanecer; IV - Roberto Barrios: el caracol que habla para todos; $V$ - Oventic: resistencia y rebeldía por la humanidad. Ressalta-se que para a festa de inauguração dos Caracóis não foram convidados nem partidos políticos nem órgãos governamentais. A ruptura para os zapatistas estava clara. Entre os esclarecimentos feitos para os novos territórios rebeldes estavam:

O EZLN não deveria ser a voz dos que mandam (...) por que o zapatismo era a voz dos de baixo, dos governados; o EZLN tinha a missão de defender os MAREZ e as Juntas de Bom Governo; os MAREZ e JBG deveriam recorrer às forças milicianas do EZLN para auxiliar no governo dos territórios rebeldes. Tinham que governar recorrendo à razão e não à força; o papel do exército é para defender e não para governar. (SubCOMANDANTE MARCOS, 2013)

As JBG se tornaram o primeiro "órgão formal" de administração dos municípios autônomos, assumindo também novas funções, de acordo com este novo ordenamento territorial, entre elas: (a) ser ponte entre as comunidades e o mundo; (b) mandar obedecendo; (c) mediar conflitos e violações dos direitos humanos; (d) vigiar e apoiar os projetos e tarefas comunitárias; (e) estar atentos ao cumprimento das leis zapatistas; ( $f$ ) guiar as visitas aos caracóis; (g) promover projetos construtivos; (h) instalar acampamentos de paz. E, assim como nos caracóis, as JBG escolheram cinco nomes, eleitos pelos conselhos autônomos: I - Hacia la esperanza; II Corazón del arco-íris y de la esperanza; III - Camino del futuro; IV - Nueva semilla que va a producir; V - Corazón céntrico de los zapatistas.

As JBG, os Caracóis e a reaparição do EZLN com uma postura cada vez mais política em relação ao movimento originalmente bélico-militar, reerguendo e rearticulando o movimento indígena mexicano sob a bandeira da autonomia:

Después de la reaparición del EZLN, 75 organizaciones indígenas de todo el país se reunieron en Chiapas. Defendieron los procesos de autonomía que se estaban ensayando y argumentaron (...) la autonomía era la alternativa. Hicieron su Plan Zapatista Reali-ti. El Consejo Guerrerense Indígena se puso a estudiar los Caracoles. En Veracruz (...) intencionaron crear JBG. Comunidades indígenas de Michoacán anunciaron que formarían 18 municipios autónomos. (...) veían las JBG como un excelente instrumento de democracia popular. $Y$ algunos sindicatos ligados a la Convergencia Sindical y Social apoyaron la 
autonomía zapatista. (ALONSO; ALONSO, 2015, p. 185-186)

Essas novas instâncias definiram novos planos e decisões de funcionamento e organicidade, ressaltando a autonomia zapatista, que não implicava "fragmentar" ou criar um movimento separatista no México, mas sim o direito de se autogovernar, reafirmando a identidade mexicana e indígena.

Ao mesmo tempo, enquanto os zapatistas fortaleciam formas de organização socioespacial paralelas ao Estado (e também contra o Estado), setores do governo se alinhavam em reanimar as forças paramilitares e as ações de repressão às comunidades zapatistas.

Quando tais interesses são colocados em jogo, o Estado não nega o recurso à violência como forma de restituir o domínio sobre tais espaços. (...) o controle territorial é justamente o ponto de tensão que a existência dos territórios autônomos zapatistas oferece ao estado mexicano. (ALKMIN, 2015, p. 60)

\section{A hidra capitalista (ou "No basta con avisar lo que vemos")}

A trajetória do movimento zapatista, desde sua formação na clandestinidade, passando pelo espetacular surgimento à luz pública, culminando (sem se encerrar) no momento atual simbolizado pelos Caracóis e pelas JBG, nos mostra as transformações e a complexificação pela qual passa a compreensão que o movimento faz de si próprio e dos/das oponentes com os quais se enfrenta.

Do movimento surgido a partir do deslocamento de um pequeno grupo de militantes formados em ambientes urbanos, que propunham uma espécie de sincretismo entre orientações maoistas e práticas indígenas, ao momento atual, uma primeira observação que nos é permitida fazer é a de sua crescente indianização. Se a aparição pública, com armas em punho e rostos cobertos, fez lembrar das guerrilhas de libertação nacional que marcaram a paisagem social do continente latinoamericano nas décadas de 1960 e 1970 - e, afinal, não era exatamente esse o objetivo impresso no nome do movimento? -, seu progressivo afastamento da política em suas esferas e concepções instituídas e tradicionais é evidência suficiente, talvez até mesmo incontestável, de que se fala aqui de uma outra política. Tão outra, tão não usual, que ainda hoje parece ser de difícil compreensão e interpretação para diversos setores, em especial - o que não chega a ser surpreendente - para aqueles vinculados à política partidária no campo das esquerdas.

Em que pesem as distintas faces apresentadas pelo movimento nessa sua trajetória de pouco mais de trinta anos de existência, é possível afirmar que seus objetivos estiveram sempre presentes e que, até mesmo, sofreram poucas alterações nessa caminhada. 0 que sim sofreu alterações foram as táticas adotadas para a consecução desses objetivos. Se a aparição pública permitiu a muitos supor que se tratava de um movimento que propunha a tomada do Estado através das armas em punho - como as Revoluções Cubana e Sandinista, de memórias ainda recentes no imaginário popular latinoamericano -, a Primeira Declaração da Selva Lacandona não permitia maiores dúvidas: o conflito evidenciado ali não era pontual, mas sim o resultado do acúmulo de 500 anos de lutas. O EZLN denunciava as condições de precariedade a que estava submetida a população chiapaneca, reiteradamente explorada em todos os momentos da trajetória histórica do país (mencionados um a um ao longo do texto da declaração). Ao aludir à memória de Emiliano Zapata como eixo articulador de sua caminhada, o EZLN recorria à Constituição originada na mesma Revolução que teve Zapata como um de seus maiores líderes, para afirmar seu direito soberano e inalienável ao autogoverno. As armas eram um recurso reconhecidamente final em sua demanda, e eram empunhadas como uma forma de exigir e de proteger uma liberdade garantida constitucionalmente, frente à guerra não declarada de que eram vítimas.

Como se nos faltassem evidências da clareza dos objetivos do movimento, recordemos que o estopim de sua decisão pela luta armada foi, exata e precisamente, a alteração do emblemático artigo 27 da Constituição mexicana, realizada em 1992 durante o governo neoliberal de Salinas de Gortari, sob os auspícios da ingerência estadunidense. 0 artigo que representava o último emblema daquela fundamental Revolução, que garantia a proteção do Estado mexicano às terras comunitárias - com todo o aparato estatal que se criara para apoiar política e economicamente aquelas comunidades -, era desmantelado em nome de uma suposta modernização do campo e das práticas agrícolas com vistas ao ingresso competitivo no mercado global. A alteração do artigo 27 era, de fato, o fim da Revolução Mexicana e das políticas pelas quais milhares de camponesas e camponeses haviam lutado e dado suas vidas. Era a consolidação de um processo político e econômico, de tons neoliberais, para o qual as comunidades camponesas eram um empecilho a ser eliminado. Zapata, então, voltava à vida para se colocar diante da dilaceração de seu legado. Agora, porém, multiplicado em milhares de homens e mulheres de rostos cobertos e de armas em punho.

A relação - temporária, ressalve-se - que o EZLN manteve com os partidos políticos de esquerda também não deve confundir nossa interpretação. Em primeiro lugar, porque é compreensível a simpatia, ou mesmo o entusiasmo, com que os zapatistas foram recebidos 
no campo de uma esquerda institucional em estado de atordoamento, ainda não recuperada do fim da utopia soviética - utopia para quem? - e confusa pelo avanço quase incontrolável das políticas neoliberais no país e no continente. Nesse cenário de perda da capacidade de mobilização, o surgimento de um movimento como o zapatista, que despertou comoção e intervenções públicas de dimensões multitudinárias, era um alento para a sobrevida de partidos e políticos a eles associados.

Se é verdade que a aproximação com os partidos não foi rechaçada pelos zapatistas, que não se diga que isso significava alguma estratégia oficial do movimento. Como visto anteriormente, as esferas de discussão propostas e efetivamente promovidas pelos zapatistas chamavam à participação os mais amplos setores da sociedade, numa expressão clara de uma articulação com "los de abajo". Mas os partidos, enquanto formas de participação política cujo horizonte é o Estado, não conseguem - desejam? - atuar fora das margens instituídas dentro das quais operam. E ficou claro, desde o princípio, que o "apoio" aos zapatistas era moeda de troca para o apoio nos pleitos eleitorais. $E$ que as agendas partidárias teriam sempre $o$ papel de protagonista nessa (frustrante) aliança.

Percebe-se que há uma caminhada lenta, progressiva - ainda que com alguns reveses e/ou recuos estratégicos -, em direção a um preceito/conceito fundamental para o entendimento da experiência zapatista: a autonomia. Afınal, não é autonomia o que se exige quando se alude à Constituição mexicana para que se cumpra o direito ao autogoverno? Não é autonomia o que está em jogo quando se recusa o dirigismo político-partidário sobre a condução do movimento? Ou, em sentido contrário, não é uma condição heterônoma ${ }^{6}$ o que se combate, enfrenta e se busca superar?

Observe-se que a escolha das palavras adotadas aqui não é aleatória: a autonomia, para os e as zapatistas, não é conceito, formulação externa - heterônoma adotada de acordo a alguma conveniência; a autonomia é preceito, é condição de existência. Há, aí, um sentido inverso em relação ao trajeto tradicionalmente percorrido pelo pensamento crítico, que é formulado, inicialmente, no ambiente fechado da academia para, posteriormente, "guiar" as aspirações dos movimentos populares. 0 movimento zapatista reflete a partir de suas próprias condições de existência para formular, de maneira autônoma, seus princípios e objetivos que podem, sim, alimentar a discussão teórico-conceitual.

Percebe-se, é certo, uma convergência entre os princípios e ideologias do movimento, e formulações

${ }^{6}$ Como afirma Souza, "a heteronomia ocorre quando as leis e normas que regem uma sociedade são deliberadas não pelo conjunto dos indivíduos pertencentes a essa sociedade de maneira lúcida e com conhecimento de causa, mas impostas de cima para baixo (opressão interna), de fora para dentro (opressão externa) e/ou 'divinizadas' ou 'naturalizadas'" (SOUZA, 2001, p. 158-159). teóricas e conceituais oriundas de diferentes geografias e de diferentes calendários. Mas nisso reside a riqueza da sociodiversidade, nas trocas, naquilo que Santos (2008) denomina "teoria da tradução", a identificação de nexos e a construção de eixos comuns. Em outras palavras: os e as zapatistas não dependem dos conceitos e teorias acadêmicas para construir sua ação. Nós, que viemos de outras geografias, é que nos amparamos em correntes teóricas diversas para tentar interpretá-los e, de alguma forma, "traduzir" o movimento de acordo com nosso léxico e com nossas referências teórico-conceituais.

Nesse sentido, voltamos ao ponto da dificuldade que o mundo "ocidental" teve na interpretação do movimento zapatista. 0 pensamento marxista não apenas quis enquadrá-los numa leitura referenciada nas contradições econômicas do capitalismo, como os partidos socialistas, no México e fora dele, ainda hoje se ressentem da ausência dos e das zapatistas nas trincheiras da sua "revolução". Já os pós-estruturalistas e pós-modernistas optaram por inseri-los na classificação de "Novos Movimentos Sociais", esquecendo-se de que essa leitura havia sido construída sobre sujeitos, eventos e mobilizações de uma origem e tempo - a geografia e o calendário - específicos e, mais do que isso, eram movimentos construídos a partir de contradições internas de sociedades de matriz ocidental. E, não é demais recordar, os próprios zapatistas se apresentaram como sendo o resultado de 500 anos de lutas o que, convenhamos, não pode ser caracterizado como "novo".

Uma possibilidade que nos parece bastante adequada para enfrentarmos a exigência de "encaixar" (ou não) o movimento zapatista em alguma "gaveta" do conhecimento acadêmico vem de uma formulação do boliviano Luis Tapia (2008): o zapatismo não seria um "movimento social", mas sim um "movimento societal". Para o autor, "movimento social" é uma categoria criada na Academia "ocidental" para a leitura de sujeitos e fenômenos próprios dessa matriz societária específica? Já o "movimento societal" é um movimento

que no proviene de la acción colectiva generada en el
seno de estructuras modernas de vida social, sino de
estructuras comunitarias de sociedades y culturas
no modernas, pero que hacen política para demandar
al gobierno una mayor integración y reconocimiento
(...). Se trata de formas sociales y políticas de origen
no moderno que se movilizan contra los efectos
expropiadores de su territorio y destructores de sus
comunidades causados por los procesos modernos de
explotación de la naturaleza. (TAPIA, 2008, p. 63)

Movimentos societais são, portanto, sociedades que

7"La noción de movimiento social emerge para pensar la constitución de sujetos críticos dentro de un tipo de sociedad; en este sentido es resultado de las contradicciones propias de un tipo de sociedad y el sistema de sus relaciones sociales, y se dirige a reformarla desde adentro, aunque contenga un proyecto de revolución o sustitución amplia de estructuras" (TAPIA, 2008, p. 62-63) 
se mobilizam no seio de uma forma (outra) de sociedade dominante. São "movimentos de sociedades", entendidas não apenas como mero agrupamento de indivíduos, mas como um conjunto singular de significados sociais construídos e partilhados coletivamente. Castoriadis (2002), autor vinculado ao pensamento autonomista e emancipatório, defende que essa singularidade das sociedades é constituída pelo que ele denomina "magma das significações imaginárias sociais":

\begin{abstract}
Há, portanto, uma unidade da instituição total da sociedade; observando-a mais de perto, descobrimos que essa unidade é, em última instância, a unidade e a coesão interna do tecido imensamente complexo de significações que impregnam, orientam e dirigem toda a vida daquela sociedade e dos indivíduos concretos que, corporalmente, a constituem. Esse tecido é o que eu chamo de magma das significações imaginárias sociais trazidas pela instituição da sociedade considerada que nela se encarnam e, por assim dizer, a animam (CASTORIADIS, 2002, p. 239)
\end{abstract}

A autonomia seria, então, a capacidade e a condição de construir para si, individual ou coletivamente, as instituições $^{8}$ que configuram formas específicas de sociedade, acordes às necessidades e aos anseios e aspirações daqueles que dela participam. Ela não se consolida, portanto, exclusivamente no espaço etéreo dos pensamentos ideais: ela deve ser posta em prática, exercitada, construída e materializada em espaço. A autonomia é a autoinstituição da sociedade que, nesse mesmo processo de pensar-se a si mesma, constrói um território que é a materialização espacial desse conteúdo social específico' ${ }^{9}$.

O vínculo conceitual sugerido aqui entre autonomia e território é análogo ao vínculo estabelecido na prática pelo movimento zapatista no processo de constituição dos Aguascalientes, dos MAREZ e, posteriormente, dos Caracóis: não haveria como viver de forma autônoma sem a constituição de espaços para o exercício dessa autonomia. A instituição de um novo imaginário social requer a instituição concomitante de uma outra territorialidade, de uma outra leitura das relações entre sociedade e espaço.

Temos então, novamente, uma contribuição dos zapatistas ao debate teórico-conceitual. Afinal, o significado dado pelo movimento aos seus territórios ultrapassa em muito a associação unívoca e unifuncional entre Estado (ou Capital, do qual é agente) e território,

\footnotetext{
8"[...] tomando aqui a palavra instituição no sentido mais amplo e mais radical normas, valores, linguagem, instrumentos, procedimentos e métodos de fazer frente às coisas e de fazer coisas e ainda, é claro, o próprio indivíduo, tanto em geral como no tipo e na forma particular que lhe dá a sociedade considerada (e em suas diferenciações: homem/mulher, por exemplo)" (CASTORIADIS, 2002, p. 237).

9"Toda sociedade ao se constituir a si mesma constitui seu espaço conformando, assim, seu território. Desse modo, o território não é uma substância externa, nem tampouco uma base sobre a qual a sociedade se erige, como queria Hegel. Ao contrário, o território é constituído pela sociedade no próprio processo em que tece o conjunto das suas relações sociais e de poder" (PORTO-GONÇALVES, 2003, p. 265)
}

entendido como mera base material, fonte de recursos "naturais" e "humanos" - distinção que está na base da racionalidade moderna - apropriados/dominados de forma indistinta para a consecução de uma única racionalidade, de um único imaginário.

Os zapatistas demonstram, na prática, que a construção da autonomia - e, por extensão, dos territórios autônomos - se dá através de múltiplas dimensões da existência. Um território não é, nem nunca será, apenas o resultado da apropriação material dos "recursos" disponíveis para fins de solução das necessidades igualmente materiais. Um território é essa apropriação material, mas é, igualmente, a compreensão de mundo e os significados construídos concomitantemente a essa apropriação física. São dimensões materiais e simbólicas que se imiscuem, se interinfluenciam, que se constroem mútua e concomitantemente. Dimensões por vezes não materiais que possuem uma contraparte concreta visível no espaço. 0 território é, para os e as zapatistas, aquilo que, em outra geografia, Porto-Gonçalves (2002) denominou como sendo uma "categoria espessa", pelo fato de que sua constituição implica todo um conjunto de práticas políticas, econômicas, sociais e culturais, que materializam, enquanto configuração territorial, um determinado imaginário social. Um território não é uma, mas múltiplas dimensões envolvidas na apropriação do espaço.

Múltiplas, como múltiplas são as cabeças da hidra ...A imagem do capitalismo como uma hidra, proposta pelo EZLN, nos parece fundamental para compreender que, muito mais do que um modo/sistema de produção/gestão econômica, o capitalismo é um modelo civilizatório, uma significação imaginária social que, portanto, influencia (ou mesmo determina) as condições vividas em múltiplos campos de existência a partir de um conjunto específico de fatores e elementos utilizados de acordo à sua instrumentalidade.

Tomar como referência a analogia da hidra significa reconhecer e afirmar que a economia - ou as relações econômicas - é "apenas" uma das cabeças da hidra capitalista - não a única, nem a mais importante. Significa reconhecer as múltiplas dimensões da existência dominadas pelo imaginário social instituído pelo capitalismo. Reconhecer o capitalismo enquanto modelo civilizatório significa reconhecê-lo enquanto um imaginário específico de sociedade, com toda a complexidade que essa interpretação carrega. Reconhecê-lo enquanto imaginário significa reconhecer que se trata de uma dominação que abrange as diferentes esferas das relações sociais, em suas formas de ser, de fazer, de criar, de produzir, de relacionar-se entre si e com os e as demais. 
A analogia zapatista também nos auxilia a ver que o capitalismo, enquanto imaginário social específico, e enquanto relação de dominação, se institui e se reproduz a partir da apropriação e/ou ressignificação de outras formas de dominação que lhe são anteriores e constitutivas. A hidra soma cabeças em sua voracidade. Derrotar a "cabeça" econômica - ou, em outras palavras, centralizar as ações no campo do trabalho, na contradição capital x trabalho, na emancipação da classe trabalhadora, não é realização suficiente para "matar a hidra". Tal como numa deposição sucessiva de sedimentos geológicos, as relações no âmbito do trabalho podem ser consideradas o estrato superior das relações de dominação existentes na sociedade capitalista. A supressão/eliminação desse estrato não elimina as outras camadas que lhe servem de sustento e que lhe são constitutivas: elas permaneceriam vigentes, enquanto estratos de localização mais profunda, por vezes menosprezados.

A experiência zapatista nos mostra uma compreensão acurada dessa sobreposição de esferas de dominação. Um exemplo esclarecedor é o fato de que, quando surgem à luz pública, uma de suas primeiras manifestações ter sido a "Lei Revolucionária das Mulheres", o que torna claro que, para o movimento, sem a emancipação da mulher, não haveria emancipação social possível. A identidade do zapatismo enquanto movimento político radical não é passível de compreensão sem o papel central exercido pelas mulheres. E se, como tão bem nos lembram os movimentos feministas das nossas geografias, numa sociedade - e território - heterônomo(s) o trânsito livre e seguro das mulheres é objetivo ainda não alcançado, nos territórios zapatistas essa é uma realidade em franco processo de transformação.

Quais seriam, então, as cabeças da hidra (ou quais as esferas a partir das quais o capitalismo exerce sua dominação)? Sem a pretensão de exaurir o debate lembremos que a própria mitologia nos oferece relatos variados quanto ao número preciso de cabeças do monstro -, vamos sugerir alguns campos que podem ser problematizados sob essa perspectiva de superação do imaginário social capitalista:

a) dominação da natureza: o apartamento entre sociedade e natureza, configurando esta enquanto objeto a ser conquistado, é um dos pilares básicos da racionalidade moderna. 0 extrativismo (mineral, principalmente) enquanto atividade central para a consolidação do capitalismo europeu;

b) dominação da mulher. pilar de um imaginário social de dominação anterior, até mesmo, aos processos coloniais, colocando a mulher, e os papéis sociais a ela atribuídos, em posição hierarquicamente inferior ao da contraparte masculina;

c) dominação da política: a instituição do Estado como esfera privativa de normatização das relações políticas na sociedade, no que se configura um verdadeiro sequestro da política das dimensões sociais, vividas e cotidianas, nas quais efetivamente se constroem as significações sociais.

d) dominação econômica: a racionalidade capitalista amparada numa leitura específica de desenvolvimento, que promove a quantificação e a individualização das relações de produção.

Estas são apenas algumas das dimensões possíveis de serem enunciadas. Como dito anteriormente, o número de cabeças pode ser maior do que o imaginado. E mais: as cabeças, quando cortadas, renascem. 0 que, de um ponto de vista da experiência real, nos serve de alerta: o capitalismo não é um sistema de dominação estático, de estruturas rígidas e permanentes. Pelo contrário: tem na dinâmica e na maleabilidade um de seus trunfos. 0 que significa dizer que, por melhores que possam ser as conquistas pontuais em uma das direções (cabeças) apontadas, é muito provável que o capitalismo se reinvente para voltar a exercer sua dominação ali mesmo onde se julgava que ela estava extinta. Como nos recorda a epopeia de Hércules, a única forma de evitar o ressurgimento de uma cabeça da hidra era queimando o exato local de onde ela havia sido cortada...

\section{Por um mundo de territorialidades autônomas (ou "un mundo donde quepan muchos mundos")}

Se é que é possível sintetizar a trajetória e a experiência zapatistas num único preceito, parecenos que essa síntese tem de conter, obrigatoriamente, a compreensão de o quão fundamental é a "estratégia territorial ${ }^{10}$ para a consecução de um objetivo tão desafiador e complexo como a autonomia. Mantendo-se, obviamente, a consciência de que essa síntese nada tem de simplificação: como visto, a espessura de um território requer a reconstrução do tecido social em múltiplas dimensões da existência.

Mas em que pesem as dificuldades dessa construção, o alerta zapatista é suficientemente claro para que possa ser ignorado: "el asunto es que lo que nosotros, nosotras, zapatistas, miramos y escuchamos es que viene una catástrofe en todos los sentidos, una tormenta"

10É possível, aqui, uma analogia com a proposta de Certeau (2008), de que "a estratégia postula um lugar suscetível de ser circunscrito como algo próprio e se a base de onde se podem gerir as relações com uma exterioridade de alvos ou ameaças. (...) O próprio é uma vitória do lugar sobre o tempo. Permite capitalizar vantagens conquistadas, preparar expansões futuras e obter assim para si uma independência em relação à variabilidade das circunstâncias. É um domínio do tempo pela fundação de um lugar autônomo" (CERTEAU, 2008, p. 99). 
(SupCOMANDANTE GALEANO, 2015, p. 27). Esse não é um alerta isolado: as denúncias da crise civilizatória que atravessamos, crise do sistema capitalista com seu imaginário social de dominação e exclusão, surgem e ecoam desde distintos setores da sociedade (academia, movimentos sociais, religiosos progressistas etc.).

A "diferença" - se é que podemos defini-la assim - do alerta zapatista é que, frente a essa ameaça de tormenta, os e as zapatistas assumem uma estratégia autônoma, posta em prática de forma sensível, diária e cotidianamente, na r-existência propositiva de reconstrução do tecido social frente aos ataques da hidra. Os Caracóis materializam espacialmente, a cada dia, formas de gestão da vida coletiva que contrastam radicalmente com as formas vivenciadas hoje em nossa sociedade regida pelos padrões dominantes da cultura ocidental e que, por isso, continuam sendo uma ameaça aos interesses associados do Estado e do capital.

E não podemos esquecer: as cabeças da hidra ressurgem e se reinventam. Se não foi possível eliminar a experiência zapatista pela força das armas, o Estado "ataca" hoje com "programas sociais" de apoio à pequena agricultura: uma forma de "seduzir" as comunidades para que não se somem às fileiras zapatistas. Um Estado paternal e benfeitor é a "cabeça" que afronta a autonomia construída naqueles territórios.

"Um mundo onde caibam muitos mundos", nos diz a consigna zapatista. Um mundo de múltiplas territorialidades, atrevemo-nos a complementar. Autônomas, insurgentes, articuladas em redes numa inovadora geopolítica de "los de abajo". Um outro mundo possível. 


\section{Referências}

ALKMIN, F. M. (2015) Por uma geografia da autonomia: a experiência de autonomia territorial zapatista em Chiapas, México. 195 fls. Dissertação (Mestrado em Geografia Humana). Universidade de São Paulo, São Paulo.

ALONSO SÁNCHEZ, J.; ALONSO REYNOSO, C. (2015) En busca de la libertad de los de abajo: la demoeleuthería. 1. ed. Guadalajara, México: Ed Universidad de Guadalajara. 487 p.

BRANCALEONE, C. (2012) Sobre o significado da experiência zapatista de autogoverno. Tese (Doutorado em Sociologia) Universidade do Estado do Rio de Janeiro, Brasil 2012.

CASTORIADIS, C. (2002) As encruzilhadas do ILabirinto: oOs domínios do homem. Rio de Janeiro: Editora Paz e Terra, 2002.

CERTEAU, M. (2008) A invenção do cotidiano: 1. Artes de fazer. Petrópolis/RJ: Vozes 2008.

EZLN. (2016) Seis Declaraciones de la Selva Lacandona y otros documentos. México/, DF: Ediciones y Gráficos Eón, 2016.

GENNARI, E. (2005) EZLN: passos de uma rebeldia. 1. ed. Ed. São Paulo: Expressão Popular 2005.

ITZU LUNA, D. (2013) El arco-íris terrestre como universal possible desde el zapatismo. Revista Argumentos, UAMXOCHIMILCO, México. Ano 26, número 73, setembro-dezembro 2013.

PORTO-GONÇALVES, C. W. (2003) A geograficidade do social: uma contribuição para o debate metodológico sobre estudos de conflito e movimentos sociais na América Latina. In: SEOANE, J. Movimientos sociales y cConflicto en América Latina. Buenos Aires: Clacso, 2003.

PORTO-GONÇALVES, C. W. (2002) Da Geografia às geo-grafias: um mundo em busca de novas territorialidades. In: CECEÑA, A. Esther E.;e SADER, Emir. La gGuerra ilnfinita: hHegemonia y terror mundial. Buenos Aires: Clacso, 2002.

SANTOS, B. S. (2008) Conocer desde el Sur: para una cultura política emancipatoria. La Paz: Clacso; Cides-Umsa; Plural Editores 2008.

SOUZA, M. L. (2001) Território do Outro, problemática do Mesmo? O princípio da autonomia e a superação da dicotomia universalismo ético versus relativismo cultural. In: ROSENDAHL, Z.; CÔRREA, Roberto R. Lobato. Religião, ildentidade e tTerritório. Rio de Janeiro: EdUERJ, 2001.

SOUZA, M. L. (1995) O território: sobre espaço e poder, autonomia e desenvolvimento. In: GOMES, P. C.; CORRÊA, R. L. (orgs.). Geografia: conceitos e temas. 5. ed. Rio de Janeiro: Bertrand Brasil, , p. 77- - 116.

SupCOMANDANTE GALEANO. (2015) De cómo llegamos a la Cofa del Vigía y lo que desde ahí miramos. In: El pensamiento cCrítico fFrente a la hHidra cCapitalista I. Participación de la Comisión Sexta del EZLN. San Cristóbal de las Casas, Chiapas: EZLN, 2015.

SubCOMANDANTE MARCOS. (2013) Entrevista sobre los orígenes del Ejército Zapatista de Liberación Nacional. In: Revista Contrahistórias: a otra mirada del clio. Año 10, Segunda serie, n. ${ }^{\circ}$ 20, mMarzo-a - Agosto de 2013.

TAPIA, L. (2008) Política salvaje. La Paz: CLACSO/Muela del Diablo/Comuna 2008. 